\title{
Angiomyofibroblastoma: a very rare tumour of vulva
}

\author{
Urvashi Verma $^{1}$, Asha Nigam ${ }^{1 *}$, Chandrakanta ${ }^{2}$, Romila Chowang ${ }^{1}$, Sadhana Bharti ${ }^{1}$
} ${ }^{1}$ Department of Obstetrics and Gynaecology, ${ }^{2}$ Department of Pathology, S. N. Medical College, Agra, Uttar Pradesh,
India

Received: 02 December 2021

Revised: 05 January 2022

Accepted: 06 January 2022

\section{*Correspondence:}

Dr. Asha Nigam,

E-mail: drurvashiverma@ rediffmail.com

Copyright: ( ) the author(s), publisher and licensee Medip Academy. This is an open-access article distributed under the terms of the Creative Commons Attribution Non-Commercial License, which permits unrestricted non-commercial use, distribution, and reproduction in any medium, provided the original work is properly cited.

\section{ABSTRACT}

Angiomyofibroblastoma is a rare benign mesenchymal tumor of vulva. Patient had history of gradually increased mass over 6 years of duration. It was painless, fibro-cystic mass of $6.8 \times 4.6 \times 2.5 \mathrm{~cm}$ hanging over right side labia majora without any menstrual or coitus difficulty. Cosmetic and risk of malignancy were the main issues. After complete examination and investigations simple excision done. Histological examination revealed mass composed of numerous capillaries and some ectatic blood vessels embedded within the hyalinised matrix. No lipomatous component was found within the tumour. Nuclear atypism and pleomorphism were absent and mitotic figures were not detected. All these were suggestive of benign mesenchymal tumor, angiomyofibroblastoma.

Keywords: Angiomyofibroblastoma, Aggressive angiomyxoma, Aggressive angifibroma

\section{INTRODUCTION}

Fletchier et al reported few cases of angiomyofibroblastoma (AMFB) of the vulva as a benign neoplasm distinct from aggressive angiomyxoma (AAM). ${ }^{1}$ AMFB is a rare non-aggressive benign mesenchymal tumour arising in the subcutaneous tissue of lower genital tract of middle-aged women, mainly in vulva and vagina. ${ }^{2-}$

It is a benign stromal tumour of lower genital tract of female, a combination of cellular angiofibroma and myofibroblastoma. It is easily confused with the bartholin gland cyst due to its presence of location on vulva. ${ }^{6-9}$

It can also occur in male genital tract such as spermatic cord, inguinal region and scrotum.

It may appears as small nodular lesion at early stage or as large pedenculated mass as presented in our case.

\section{CASE REPORT}

\section{Clinical summary}

The patient 46 years old para 2 live 2 abortion 0 presented to gynaecology outpatient department of S.N Medical College Agra, with asymptomatic pedenculated mass of $6.8 \times 4.6 \times 2.5 \mathrm{~cm}$ on right labia majora. Swelling was firm to cystic in consistency. It was painless. The patient first noticed the swelling 6 year back. Initially it was a small grape like size, but it gradually increased in size. Due to the COVID pandemic situation she did not reported earlier. But increasing mass increasing her anxiety and she came to us for evaluation and rule out any neoplastic lesion. On gynaecological examination her uterus was normal in size and texture and adnexa was also non tender and not-palpably enlarged. There was mass of around $6 \mathrm{~cm}$ into $3 \mathrm{~cm}$, pedunculated, mobile, non-tender with regular and smooth surface over middle of right side of labia majora. No inguinal lymph node was palpable. 
On ultrasound of the mass- a defined hypoechoic solid mass is seen in the right labia majora. Which measure $6.8 \times 4.6 \times 2.5 \mathrm{~cm}$ margins are hypoechoic. On Doppler examination, vessels are seen in the mass as well as the periphery. Slowing avid intrinsic vascularity with low resistance waveform, lesion is heterogenous in consistency with interspersed hypoechoic and hyperechoic areas seen within it. Subsequently fine needle aspiration and cytology (FNAC) of mass revealed only blood in it. Based on clinical, ultrasound and FNAC findings we decided the surgical excision of the mass.

Patient admitted one day before the surgery. Her all the blood investigations were within the normal limit. Her simple excision of the mass through the base was done under short general anaesthesia.

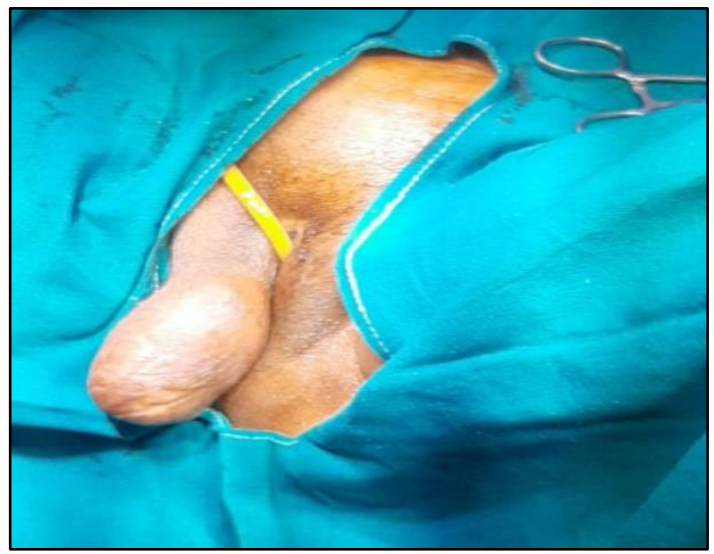

Figure 1: Vulval mass.

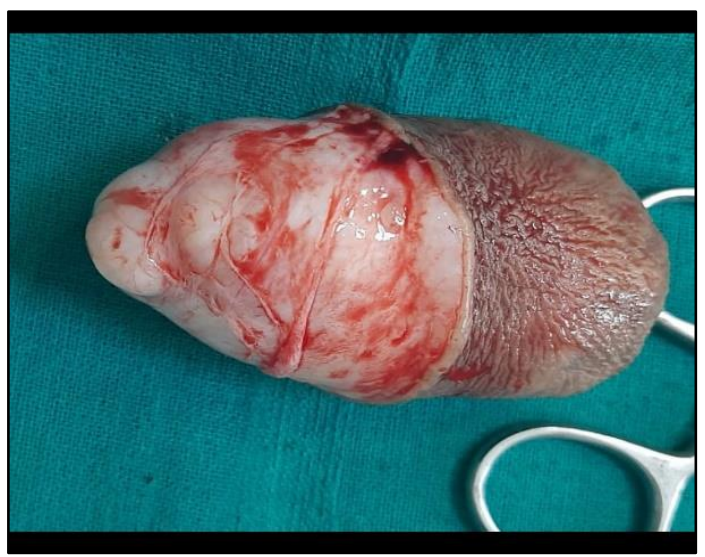

Figure 2: Angiomyobibroblastoma - on goss examination.

Gross examination- well circumscribed from the surrounding tissue. Tumour was soft to firm in consistency.

Cut surface- AMFB was homogenous greyish white cut surface with occasional haemorrhagic area.
On histological examination- multiple sections examined shows well circumscribed mass composed of numerous capillaries and some ectatic blood vessels embedded within the hyalinized matrix. Stromal cells are plump, oval to spindled with bland nuclei, whispy eosinophilic cytoplasm some of the ectatic vessels are surrounded by eosinophilic epitheloid cells which blend or fanout from muscular wall of vesels. Admixed adipocytes are also noted. Overall features are suggestive of AMFB. No lipomatous component was found within the tumour. Nuclear atypism and pleomorphism were absent and mitotic figures were not detected. On the basis of these characteristics, a diagnostic of AMFB was made.

Patient came to us for follow up after one month of her operation. Her stitch line was healthy.

\section{DISCUSSION}

We reported this case as we have never seen such case in more than 20 years of our career and reached to diagnosis only after excision and histopathology. AMFB is first described by Fletcher et al as a benign soft tissue tumor of the vulvular region which should be distinguished from aggressive angiomyxoma. AMFB consist of a diffuse proliferation of myofibroblast and small and medium sized blood vessels. The median age of AMFB is 45 years. It is painless, patient noticed it due to it's enlargement. Due to it's low frequency AMFB is confused with the bartholin cyst, lipoma, or inguinal hernia and other mesenchymal tumors of vulvular region such as cellular angiofibroma, superficial myofibroblastoma and superficial anxiomyxoma. ${ }^{10-12}$ Among mesenchymal tumors of vulva aggressive angiofibroma (AAF) is a slow growing tumor and attain a large mass which infilterates pelvic cavity, and because of difficulty on removal it's recurrence is frequent. Because both the tumor (AMFB and AAF) contain fibroblast and myofibroblast proliferation along with presence of small to medium sized blood vessels, diagnosis is difficult. ${ }^{13,14}$ The usefulness of MRI for the correct preoperative diagnosis of angiomyofibroblastoma has been documented by several studies. ${ }^{15,16}$

The diagnosis of AMFB is complicated because it's histologic picture resembles to other soft tissue tumour of lower genital tract. The differentiating feature between AAM and AMFB on histology is, in AMFB has alternating area of hyper and hypocellularity with stromal cells around small blood vessels. In contrast to AAM there is no hypercellular area and stromal cells are uniformly distributed with no perivascular attenuation. AMFB is also confused with the cellular angiofibroma (CA), both have prominent vascular components and stromal cells and adipocytes. But the differentiating feature is the presence of round tumour cells around vessels and lack of thickwalled hyalinised vessels and wispy collagen bundles helps distinguish AMFB for CA. The adipocytes tissue presents in the AMFB and Laskin et al have proposed that lipomatoes variant of AMFB contain adipose tissue. 


\section{CONCLUSION}

AMFB is defined as a benign, site specific soft tissue tumour of lower genital tract with alternating hypo and hypercellular zone, bland spindle to epitheloid cells and abundant vessels. It is prominently found in women. There is no specific immunophenotypic or molecular feature reported. Local excision is the curative method. Recurrence is exceptionally rare.

Funding: No funding sources

Conflict of interest: None declared

Ethical approval: Not required

\section{REFERENCES}

1. Fletcher CD, Tsang WY, Fisher C, Lee KC, Chan JK. Angiomyofibroblastoma of the vulva. A benign neoplasm distinct from aggressive angiomyxoma. Am J Surg Pathol. 1992;16:373-82.

2. Onckner DM, Sayadi H, SwansonPE, Ritter JH, Wick MR. Genital angiomyofibroblastoma. Comparison with aggressive angiomyxoma and other myxoid neoplasm of skin and soft tissue. Am J Clinc Pathol. 1997;107:36-44.

3. Fukunga M, Nomura k, Doi K Endo Y, Ushigome S. Vulvular angiomyofibroblastoma. Clinicopathologic analysis of six cases. Am J Pathol. 1997;107:45-51.

4. Hisaoka M, Kouho H, Aoki T, Daimaru Y, Hashimoto H. Angiofibroblastoma of the vulva. A clinicohistologic study of seven cases. Pathol Int. 1995;45:487-92.

5. Laskin WB, Fetsh JF, Mostofi FK. Angiofibroblastoma like tumor of the male genital tract: analysis of 11 cases with comparison to female angimyofibroblastoma and spindle cell lipoma. Am J Surg Pathol. 1998;22:6-16.

6. Ockner DM, Sayadi H, Swanson PE, Ritter JH, Wick MR. Genital angiomyofibroblastoma. Comparison with aggressive angiomyxoma and other myxoid neoplasm of skin and soft tissue. Am J Clinc Pathol. 1997; 107:36-44.
7. HSU IH, Chang TC, Wc CT Chen RJ, Chow SN. Angiofibroblastoma of the vulva. J Formos Med Assoc. 2004;103:467-71.

8. Granter SR, Nucci MR, Fletcher CDM. Aggressive angiomyxoma : reaapprasial of it's relationship to angiomyofibroblastoma in a series of 16 cases. Histopathology. 1997;30:3-10.

9. Nucci MR and Fletcher CDM: Vulvovaginal soft tissue tumor: upgrade and review. Histopathology. 2000;36:97-108.

10. Iwasa Y, Fletcher CD. Cellular angiofibroma. Clinicopathologic and immunohistochemical analysis of 51 cases. Am J Surg Pathol. 2004;28:1426-35.

11. Laskin WB, Fetsh JF, Tavassoli FA. Superficial cervicovaginal myofibroblastoma. Fourteen cases of distinctive mesenchymal tumor arising from the specialized subepithelial stroma of the lower genital tract. Hum Pathol. 2001;32:715-25.

12. Fetsh JF Laskin WB, Tavassoli FA. Superficial angiomyxoma (cutaneous myxoma). A clinicpathologic study of 17 cases arising in the genital region. Int J Gynecol Pathol. 1997;16:325-34.

13. Steeper TA, Rosai J. Aggressive angiomyxoma of the female pelvis and perineum. Report of 9 cases of a distinctive type of gynecolgic soft tissue neoplasm. Am J Surg Pathol. 1983;7:463-75.

14. Fetsch JF, Laskin WB, Lefkowitz M, Kindblom JM. Aggresssive angiomyxoma. A clinicopathologic study of 29 female patients. Cancer. 1996;78:79-90.

15. Geng J, Hu S, Wang F. Large paravaginal angimyofibroblastoma. Magnetic Resonance Imaging findings. Jpn J Radiol. 2011;29:152-5.

16. Shintaku M, Noda H, Hashimoto. Large polypoid angiomyofibroblastoma of the vulva. Int J Clinc Exp Pathol. 2018;11(11):5509-13.

17. Chapel DB, Bennet J. Angiofibroblastoma. Pathology. 2021;3:14-8.

Cite this article as: Verma U, Nigam A, Chandrakanta, Chowang R, Bharti S.

Angiomyofibroblastoma: a very rare tumour of vulva. Int J Reprod Contracept Obstet Gynecol 2022;11:607-9. 